Pak. j. sci. ind. res. Ser. A: phys. sci. 201457 (1) 47-52

\title{
Effect of Repeated Laundering on Durability and Bactericidal Activity of Some Antibacterial Finishes
}

\author{
Iram Abdullah ${ }^{a *}$, Syed Qummer Zia Gilania and Fathia Mubeen ${ }^{b}$ \\ ${ }^{a}$ National Textile University, Faisalabad, Pakistan \\ ${ }^{b}$ National Institute for Biotechnology and Genetic Engineering (NIBGE), Faisalabad, Pakistan \\ (received November 29, 2012; revised January 23, 2013; accepted January 24, 2013)
}

\begin{abstract}
This paper investigates imparting antibacterial properties to a woven and a knitted cotton fabric using polyhexamethylene-biguanide hydrochloride (PHMB), silver salt and 5 chloro-2-(2,4-dichlorophenoxy) phenol based commercially available finishes. The antibacterial functions of the treated fabric samples are determined by the nature of the bacteria as well as number of repeated washing cycles. This research shows that these finishes are more effective against species of perspiration bacteria than Escherichia coli. A higher concentration of finishes is required to improve their effectiveness against $E$. coli and their durability to repeated laundering. The effect of antibacterial finishes on the tensile strength and burst strength of woven and knitted fabrics has also been investigated, respectively. The antibacterial finishes have no drastic effect on tensile strength and burst strength of the fabrics.
\end{abstract}

Keywords: antibacterial finish, E. coli, cotton, polyhexamethylene-biguanide hydrochloride, chlorinated phenoxy compound, silver salt

\section{Introduction}

Cotton textiles are excellent substrate for microbial growth (Gao and Cranston, 2008) and their growth causes a range of undesirable effects on textile articles such as bacterial and fungal originated odours, stains, discolouration, reduction in the fabric strength and skin irritation. The environmental concern to the public is the likelihood of cross-transmission of diseases in hospitals and partially or completely unhealthy indoor air quality in working areas is caused by the contaminated textiles (Chen-Yu et al., 2007; McQueen et al., 2007; Flindt, 2006; Purwar and Joshi, 2004; Payne and Kudner, 1996). Antimicrobial processed fabrics are expected to be able to completely eliminate these concerns (Gouda et al., 2008; Gouda and Ibrahim, 2008). Biocidal agents kill bacteria however, they act on slow-release mechanism and are anticipated to be durable to washing if sufficient agents are incorporated into the fabric material (Gao and Cranston, 2008; Purwar and Joshi, 2004). Hospitals spend a great deal of funds on sterilisation of reusable textile items. Sterilised items still have risk of contamination due to process ineffectiveness as well as recontamination after sterilisation. In an effort to assure that no contamination is present, fabrics with biocidal properties offer an attractive alternative for this problem.

*Author for correspondence; E-mail: i_tayyab@hotmail.com
To date considerable work has been done on biocides for medical textiles and agents which will inactivate microorganisms. However, very less information is available for the use of biocidal agents for textile fabrics. The product designing of textile fabrics involve optimisation of treatment which should improve antibacterial characteristics parallel to performance properties of fabrics or it should not have any adverse effects on performance properties. In this study the most common antibacterial agents like polyhexamethylene-biguanide hydrochloride (PHMB), silver salt and 5 chloro-2-(2,4-dichloro phenoxy) phenol are imparted to cotton fabrics to observe (a) the antibacterial activity of finishes against Escherichia coli and bacteria isolated from sweated cloths using agar plate test (Standard Method AATCC 147, (b) the impact of treatments on tensile and burst strength of cotton fabrics using Standard Methods ASTM D 5035-06 and ASTM D3786-01, respectively, (c) the durability of antibacterial treatment to laundering using Standard Method BS EN ISO 15487: 2001.

\section{Materials and Methods}

Materials. A $100 \%$ woven fabric of 1/1 plain weave, $64 \times 60 / 25 \times 24$ quality, $111 \mathrm{~g} / \mathrm{m}$ weight and a $100 \%$ knitted fabric of 3 wales/inch, 37 course/inch, 20.3 count and $150 \mathrm{~g} / \mathrm{m}$ weight, obtained from Yarn Market Faisalabad, were used throughout this study. The fabric 
samples were treated with three different chemical classes of antimicrobial compounds through conventional pad-dry-cure procedure. Reputex 20; a polyhexamethylene biguanide hydrochloride (PHMB) compound, was obtained from BASF. Silpure FBR-5; silver salt based compound was obtained from CIBA. Ultrafresh NM-V2; 5 chloro-2-(2,4-dichlorophenoxy) phenol compound was obtained from Thomson Research Associates Ltd. Acetic acid and sodium hydroxide of local grade were used to maintain the required $\mathrm{pH}$ of padding bath.

Fabric treatments. Reputex 20 was applied at 1, 1.5 and 2\% chemical, Silpure FBR-5 was applied at 1, 1.25 and $1.5 \%$ chemical, and Ultrafresh NM-V2 was applied at 2, 3 and $5 \%$ chemical on the dry weight of the fabric to ensure good antibacterial properties as recommended by the suppliers. The bath $\mathrm{pH}$ levels for chemicals Reputex 20, Silpure FBR-5 and Ultrafresh NM-V2 were 4,6 and 4, respectively.

The fabric samples $\left(30 \times 42 \mathrm{~cm}^{2}\right)$ were impregnated in the pad bath containing antibacterial compound for 5 min. The samples were padded through the squeeze rollers of TSUJII padding mangle to obtain $80 \%$ pickup, then dried in TSUJII stenter for $1 \mathrm{~min}$ at $110^{\circ} \mathrm{C}$, and finally cured for $45 \mathrm{sec}$ at $150^{\circ} \mathrm{C}$.

Fabric evaluation. The qualitative method, agar plate test (AATCC 147) was used to test the antimicrobial activity of the untreated fabrics and all treated fabrics against E. coli and perspiration bacteria. The perspiration bacteria were isolated from the sweated cloths in four replicates. $500 \mathrm{~mL}$ nutrient agar medium was prepared and sterilised by autoclaving for $20 \mathrm{~min}$ at 15 psi and $121^{\circ} \mathrm{C}$. Petri plates were autoclaved and dried in hot air oven. $20 \mathrm{~mL}$ of nutrient agar was poured into each of the plates and allowed to solidify. The culture was then transferred to the agar surface of the plate in five parallel streaks to test $E$. coli, and a bacterial lawn was used to test perspiration bacteria. A $100 \mu \mathrm{L}$ of perspiration bacteria was poured onto the agar surface and spread by using sterilised spreader. Circular cut fabric pieces were placed in the center of the plates. The sample plates were then incubated at $37{ }^{\circ} \mathrm{C}$ for 24-48 h. A clear area of interrupted growth underneath and along the sides of the test fabric indicated the antibacterial activity. In qualitative testing, the zone of inhibition was calculated for different fabrics.

Prior to testing all fabric samples were conditioned at $65 \% \mathrm{RH}$ and $20^{\circ} \mathrm{C}$. The tensile strength of unwashed,
5 and 25 times washed woven fabric samples were evaluated using standard procedure ASTM D 5035-06. The burst strength of unwashed, 5 and 15 times washed knitted fabric samples were evaluated using standard procedure ASTM D3786-01. The treated samples were washed according to standard procedure BS EN ISO 15487: 2001 at $40{ }^{\circ} \mathrm{C}$ for 100 min with an additional load of $1 \mathrm{~kg}$ (polyester fabric) then air dried.

\section{Results and Discussion}

Figures 1-3 represents the bactericidal activity of cotton woven fabrics finished with Reputex 20, Silpure FBR-5 and Ultrafresh NM-V2 applied against $E$. coli and perspiration bacteria, respectively. It was observed that the increased concentrations of finishes appeared to increase their antibacterial effect against $E$. coli and perspiration bacteria. Knitted fabrics showed better zone of inhibition values than woven fabrics due to better penetration of finishes in its open structure. Knitted fabrics showed steady decrease in zone of inhibition as laundering cycles were increased to 5 and then to 15 .

In case of woven fabrics, regardless of their chemical nature, the bactericidal response of fabric samples finishes with lower concentrations appeared to diminish after five laundering cycles. Fabric samples finishes with higher concentrations showed steady decrease in zone of inhibition as laundering cycles were increased to 25 . The existence of finishes on the fabrics and the ability of fabrics to combat bacteria after 25 washes indicated that a relatively higher concentration is required to improve the durability of finishes on woven fabric.

Among all the finishes fabrics treated with Reputex 20 showed better antibactericidal activity against perspiration bacteria. Reputex 20, chemically PHMB is a polymeric polycationic amine that binds to cellulose via an acid base interaction. The electrostatic interaction dominates at lower concentrations, however, at higher concentrations, the hydrogen bonding results in multilayer adsorption of PHMB (Simoncic and Tomsic, 2010; Abo-Shosha et al., 2008; Abo-Shosha et al., 2007; Moore and Gray, 2007; Blackburn et al., 2006), hence, improved the laundering durability of treated fabrics. Ultrafresh NM-V2 and Silpure FBR-5 do not establish any interaction with cellulose. Ultrafresh NM-V2 chemically 5 chloro-2-(2, 4-dicholoro phenoxy) phenol diffuses into the fibres and inhibit the growth of microorganisms by blocking the synthesis of lipids (Yazdankhah et al., 2006; Purwar and Joshi, 2004). 
(a)
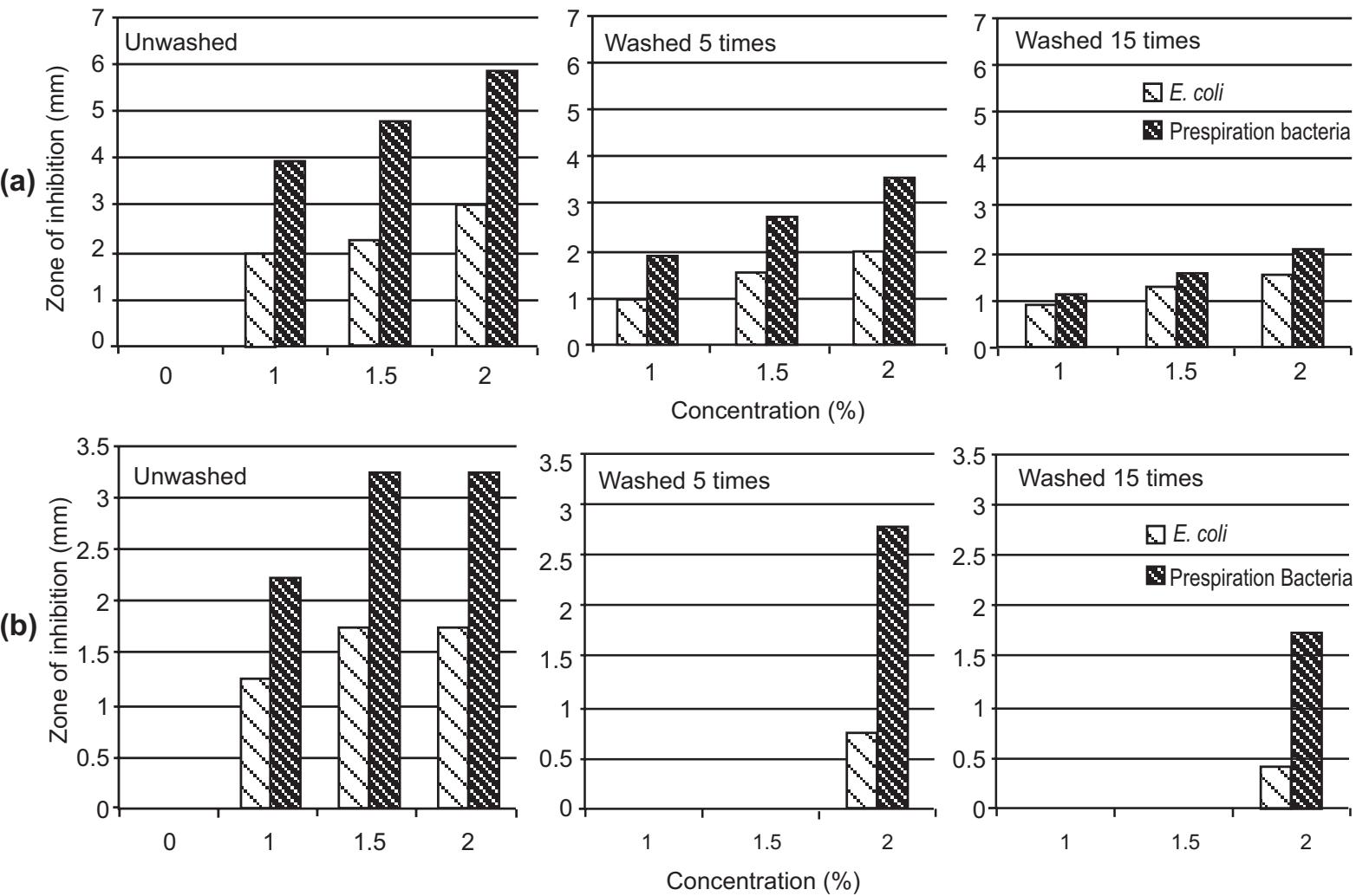

Fig. 1. Antibacterial activity of unwashed and washed Reputex 20 treated (a) knitted fabrics and (b) woven against $E$. coli and perspiration bacteria; zone of inhibition ( $\mathrm{mm}) v s$ concentration (\%).

(a)
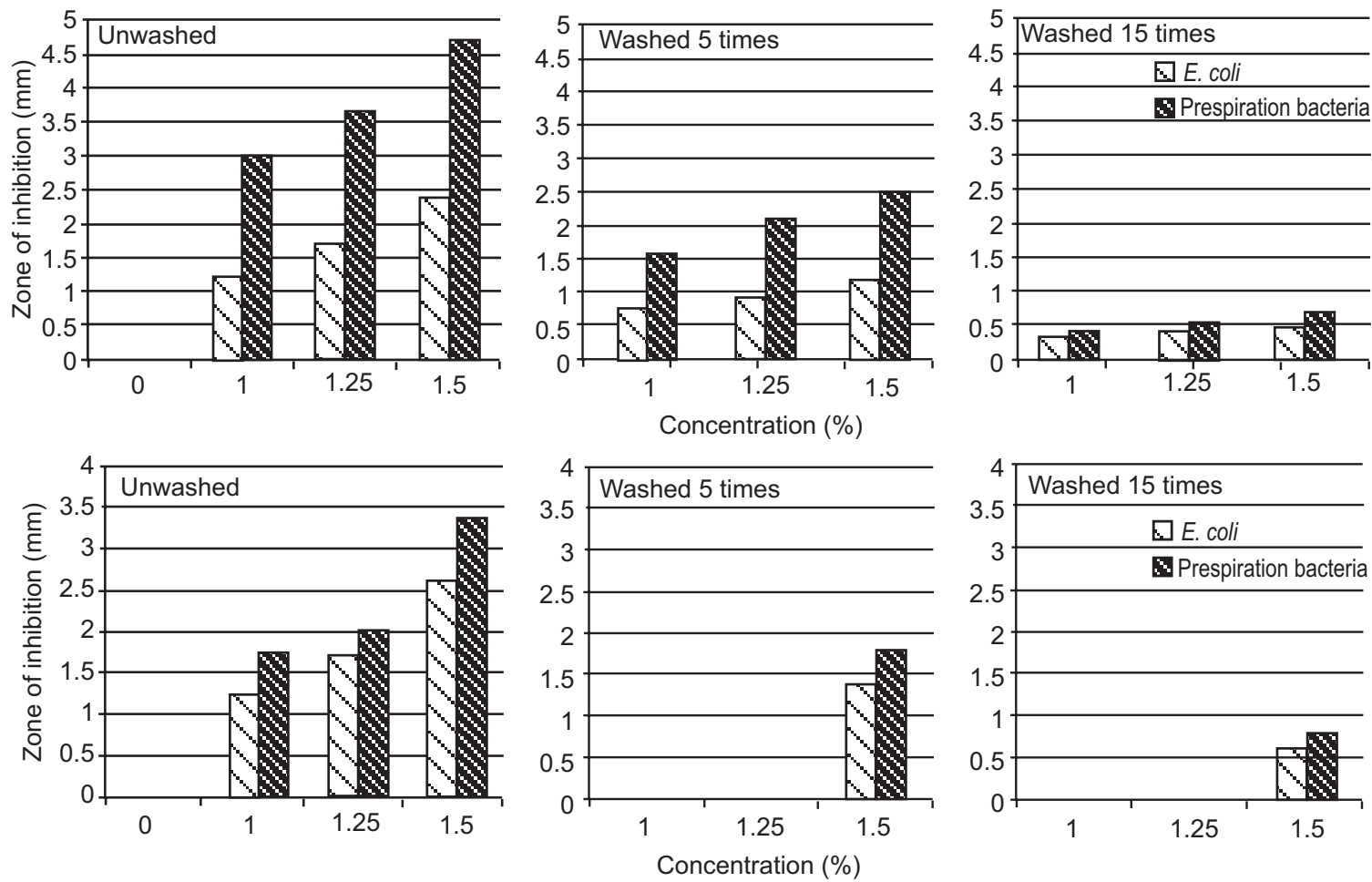

Fig. 2. Antimicrobial activity of unwashed and washed Silpure FBR-5 treated (a) knitted fabrics and (b) woven against $E$. coli and perspiration bacteria; zone of inhibition $(\mathrm{mm}) v s$ concentration (\%). 
(a)

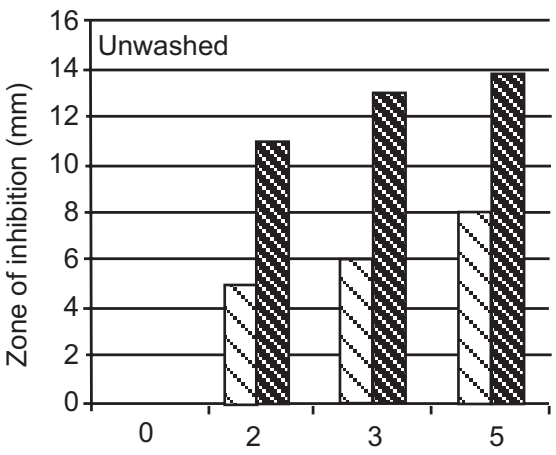

(b)

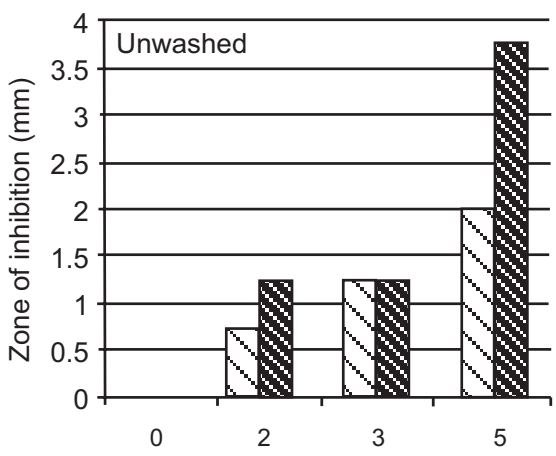

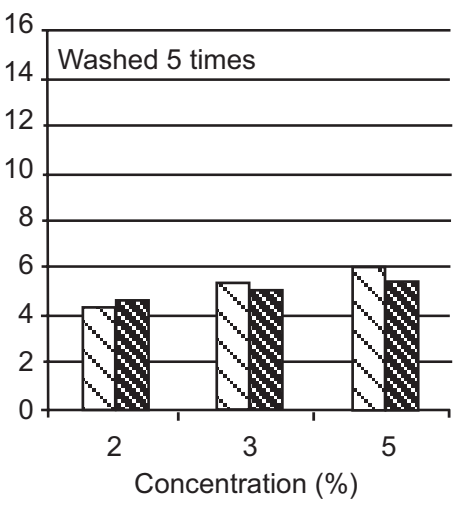
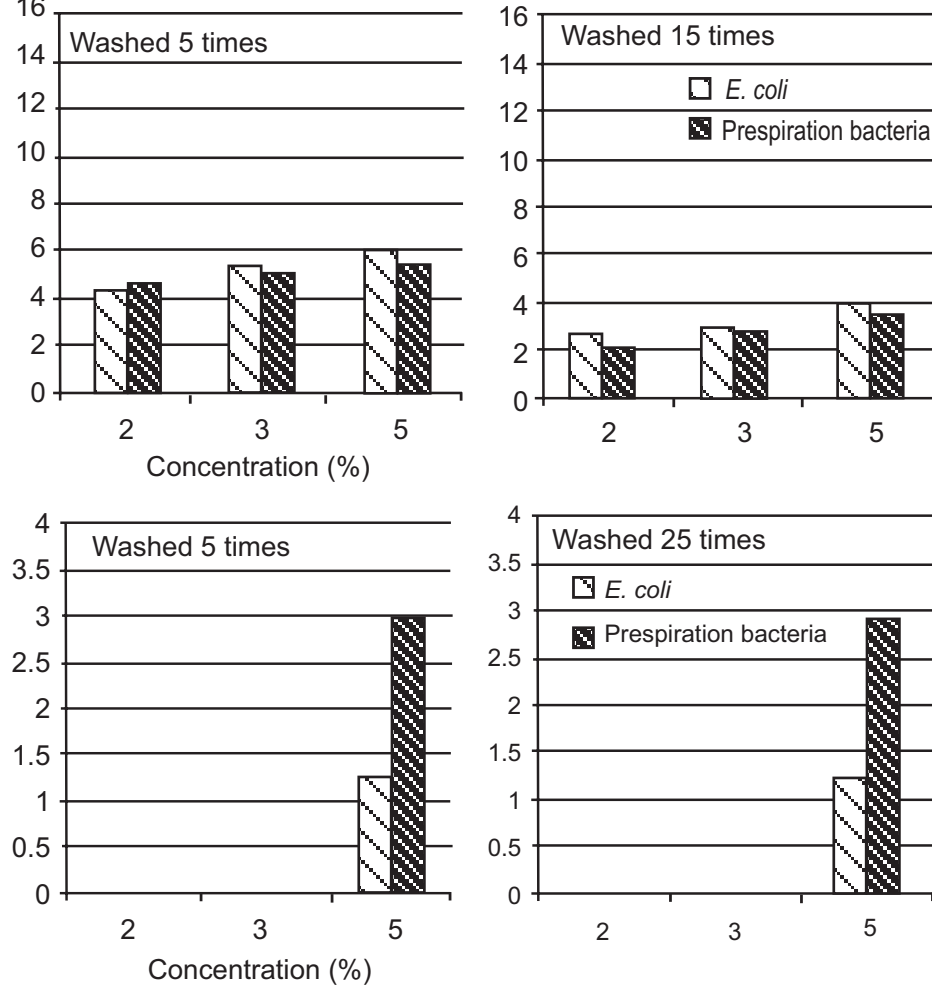

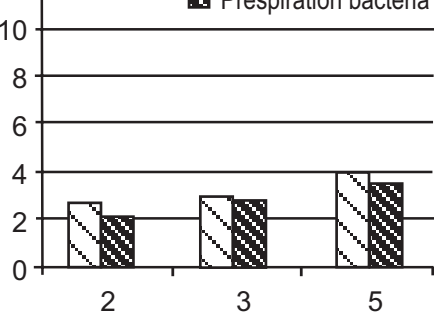

2

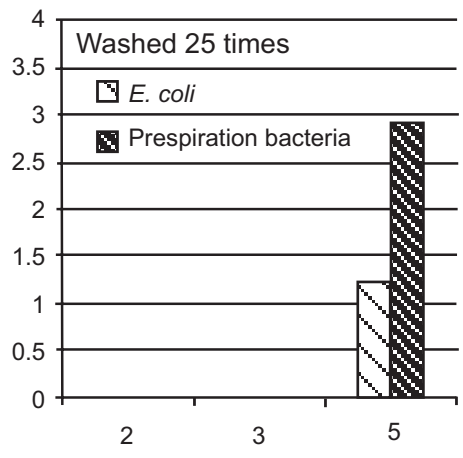

Fig. 3. Antimicrobial activity of unwashed and washed Ultrafresh NM-V2 treated (a) knitted and (b) woven fabrics against $E$. coli and perspiration bacteria; zone of inhibition $(\mathrm{mm}) v s$ concentration (\%).

During use of fabric, it migrates to the surface of treated textiles at a slow sustained rate to provide excellent antimicrobial efficacy (Chen-Yu et al., 2007; Purwar and Joshi, 2004) and laundering durability as can be seen from the results. There is slight reduction in bactericidal activity of treated fabrics after 5,15 (in case of knitted fabrics) and 25 (in case of woven fabrics) laundering cycles. Furthermore, Ultrafresh NM-V2 treated fabrics also showed better bactericidal activity against $E$. coli compared with the fabrics treated with Reputex 20 and Silpure FBR-5. E. coli; gram-negative bacteria have an additional layer of outer membrane. This extra cell wall gives cell protection and makes these bacteria more persistent in survival and more difficult to be inhibited than gram-positive bacteria (Chen-Yu et al., 2007). Silpure FBR-5; silver metal salt exerts a detrimental effect upon bacteria (Thomas et al., 2010; Williams et al., 2005; Lansdown, 2002; Nakashima et al., 2001), however, it require a crosslinking agent to establish its structure on the fibre surface and to control the release of metal ions which consequently prolong the release time and improves wash durability and resistance (Simoncic and Tomsic,
2010; Purwar and Joshi, 2004). In this study Silpure FBR-5 was applied to woven as well as knitted fabrics without cross-linking agent and its absence had caused drastic reduction in bactericidal activity in laundered fabrics.

Application of antibacterial finishes, regardless of their chemical nature, caused slight reduction in the tensile strength of treated fabrics as compared with the tensile strength of original fabric. Repeated laundering caused further reduction in tensile strength values as shown in Fig. 4. The reduction in tensile strength of treated fabrics after 5 and 25 repeated laundering cycles is not due to change in morphological behaviour of fabrics as these finishes are not chemically attached to the fabric but infact is due to the mechanical action of washing drum. The ability of fabric to move freely is very low due to high loading and small diameter of drum. Swelling of the fibres reduces slippage and cause damage to fibres which consequently reduced the tensile strength of woven fabrics. The open structure of knitted fabrics allowed fibre slippage and consequently caused less damage to fibres. There is no considerable reduction in 

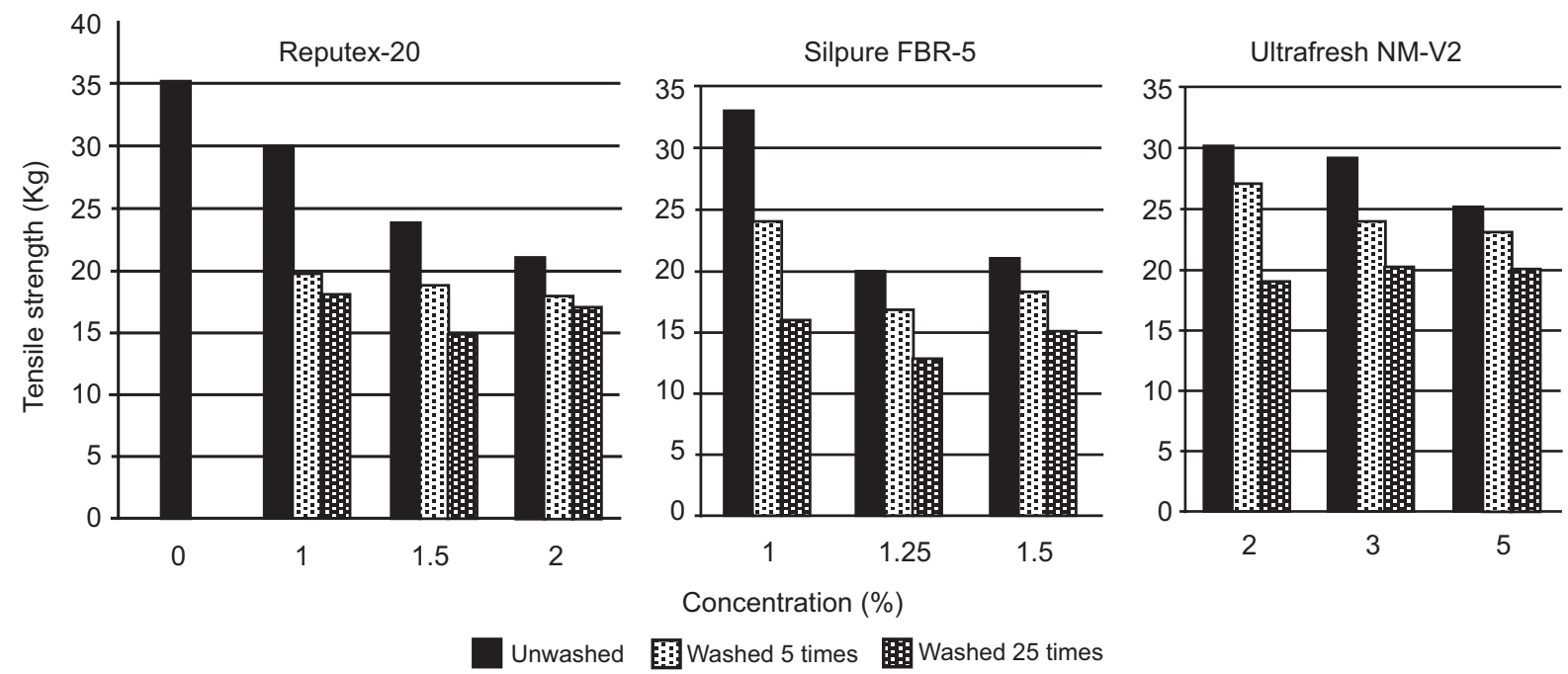

Fig. 4. Tensile strength $(\mathrm{kg})$ of antibacterial finishes woven fabrics $v s$ concentration (\%) of finishes.
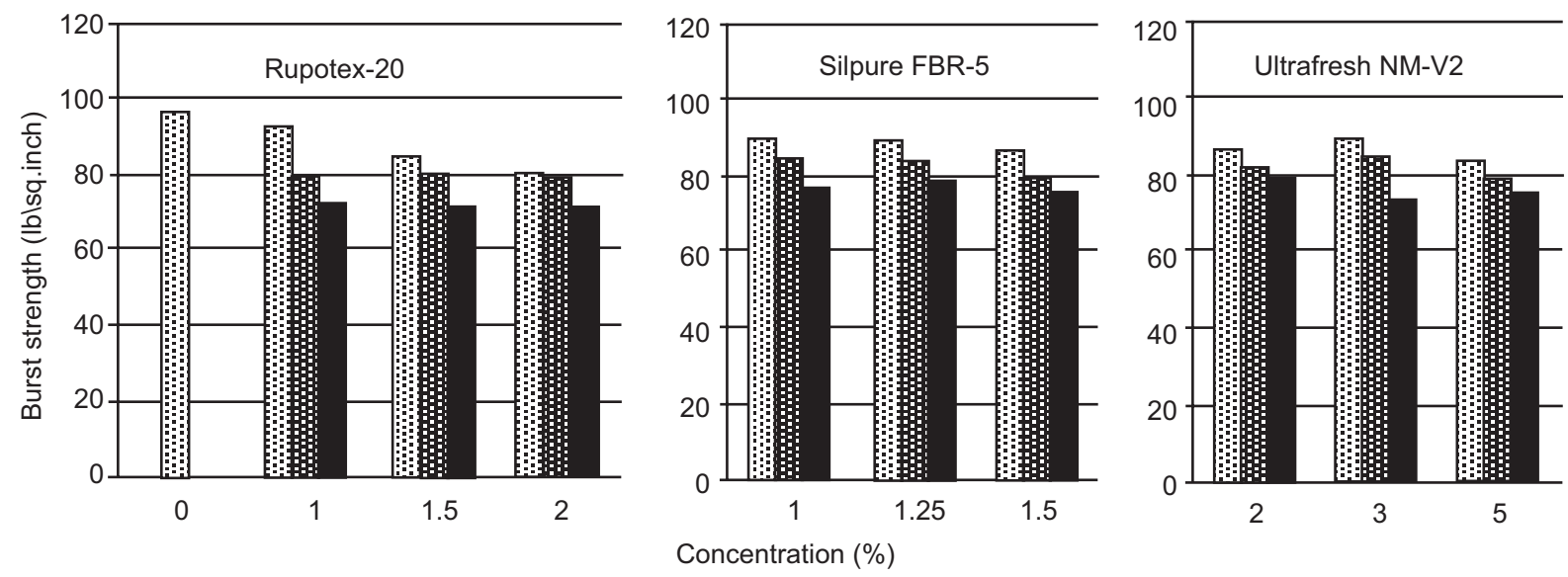

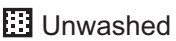

目眲 Washed 5 times

Washed 25 times

Fig. 5. Burst strength (lb/sq inch) of antibacterial finishes knitted fabrics $v s$ concentration (\%) of finishes.

burst strength of treated fabrics as compared with the burst strength of original fabric and then subsequent 15 laundering cycles caused slight reduction in burst strength of treated fabrics as shown in Fig. 5. This also indicates that antibacterial finishes has no drastic effect on burst strength of fabrics.

\section{Conclusion}

Three commercially available bound finishes Reputex 20, Silpure FBR-5 and Ultrafresh NM-V2 were applied to woven and knitted cotton fabrics. The loose structure of knitted fabric allowed better penetration of finishes into the fibre structure which consequently showed (a) better zone of inhibition against species of perspiration bacteria and E. coli, (b) better durability to repeated laundering. All three finishes are more effective against species of perspiration bacteria than E. coli, however, the bactericidal activity of Silpure FBR-5 finished fabrics is lower than Ultrafresh NM-V2 and Reputex 20. The finishes have no considerable effect on tensile and burst strength of woven and knitted fabrics, respectively. The durability of the finishes to repeated laundering showed that bactericidal activity against bacteria decreased as number of laundering cycles increased. The results conclude that the effectiveness of an antimicrobial finish depends upon the 
concentration of the finish and the effectiveness of interaction developed between the finish and the fibre.

\section{References}

Abo-Shosha, M.H., El-Hosamy, M.B., Hashem, A.M., El-Nagar, A.H. 2008. Easy care finishing of knitted cotton fabric in presence of a reactive-type antibacterial agent. Journal of Industrial Textile, 38: 103-126.

Abo-Shosha, M.H., El-Hosamy, M.B., Hashem, A.M., El-Nagar, A.H. 2007. A leaching type antibacterial agent in the easy-care finishing of knitted cotton fabric. Journal of Industrial Textiles, 37: 50-77.

Blackburn, R.S., Harvey, A.L., Kettle, L., Payne, J.D., Russell, S.J. 2006. Sorption of poly(hexamethylenebiguanide) on cellulose: mechanism of binding and molecular recognition. Langmuir, 22: 56365644.

Chen-Yu, J.H., Eberhardt, D.M., Kincade, D.H. 2007. Antibacterial and laundering properties of AMS and PHMB as finishing agents on fabric for health care workers' uniforms. Cloth \& Textiles Research Journal, 25: 258-272.

Flindt, R. 2006. Amazing Numbers in Biology, pp. 295, Springer-Verlag: Berlin, Germany.

Gao, Y., Cranston, R. 2008. Recent advances in antimicrobial treatments of textiles. Textile Research Journal, 78: 60-72.

Gouda, M., Aly, A.A., Ibrahim, N.A. 2008. Enhancing the antibacterial properties of cotton fabric. Journal of Industrial Textiles, 37: 203-212.

Gouda, M., Ibrahim, N.A. 2008. New approach for improving antibacterial functions of cotton fabric. Journal of Industrial Textiles, 37: 327-339.

Lansdown, A.B.G. 2002. Silver-I: its antibacterial properties and mechanism of action. Journal of Wound Care, 11: 125-130.

McQueen, R.H., Laing, R.M., Heather, J.L., Niven, B.E., Niven, B.E. 2007. Odor intensity in apparel fabrics and the link with bacterial populations. Textile Research Journal, 77: 449-456.

Moore, K., Gray, D. 2007. Using PHMB antimicrobial to prevent wound infection. Wounds UK, 3: 96-102.

Nakashima, T., Sakagami, Y., Ito, H., Matsuo, M. 2001. Antibacterial activity of cellulose fabrics modified with metallic salts. Textile Research Journal, 71: 688-694.

Payne, J.D., Kudner, D.W. 1996. A durable antiodor finish for cotton textiles. Textile Chemist and Colorist, 28: $28-30$.

Purwar, R., Joshi, M. 2004. Recent developments in antimicrobial finishing of textiles-A review. American Association of Textile Chemists and Colorist Review, 4: 22-26.

Simoncic, B., Tomsic, B. 2010. Structures of novel antimicrobial agents for textiles-A review. Textile Research Journal, 80: 1721-1737.

Thomas, V., Bajpai, M., Bajpai, S.K. 2010. In situ formation of silver nanoparticles within chitosanattached cotton fabric for antibacterial properties. Journal of Industrial Textiles, 40: 229-245.

Williams, J.F., HaloSource, V., Cho, U. 2005. Antimicrobial functions for synthetic fibers: Recent developments, American Association of Textile Chemists and Colorist Review, 5: 17-21.

Yazdankhah, S.P., Scheie, A.A., Høiby, E.A., Lunestad, B.T., Heir, E., Fotland, T.O., Naterstad, K., Kruse, H. 2006. Triclosan and antimicrobial resistance in bacteria: An overview. Microbial Drug Resistance, 12: 83-90. 